\title{
A arte literária nas aulas de inglês: uma abordagem baseada no Letramento Crítico
}

\section{The Literary Art in the English Classes: an approach based on Critical Literacy}

https://doi.org/10.34112/2317-0972a2020v38n78p145-157

Nayara Stefanie Mandarino Silva ${ }^{1}$

RESUMO: O PIBID/Inglês, projeto vinculado à Universidade Federal de Sergipe e à CAPES, tem como um dos objetivos desenvolver atividades que colaborem com o desenvolvimento do pensamento crítico e ampliação da visão de mundo dos que nele estão envolvidos, fundamentando-se na teoria do Letramento Crítico. Assim, esse trabalho propõe uma análise de como a literatura, que por muitos autores é reconhecida como uma aliada na formação integral dos indivíduos, foi utilizada no desenvolvimento de um dos subprojetos do referido PIBID. Para tal fim, na execução do projeto foram feitas análises que se utilizaram do livro de L. Frank Baum, The wizard of $\mathrm{Oz}$ (1983), e pesquisas do tipo qualitativa-bibliográfica de obras de autores como Candido (1999), Coradim (2007) e Freire (1989). Trata-se de um estudo exploratório, voltado para a reflexão sobre o uso de obras literárias nas aulas de inglês e de como isso pode colaborar para o alcance dos objetivos propostos pelo PIBID/Inglês.

Palavras-chave: Literatura; PIBID; aula de inglês.

Aвstract: The PIBID/English linked to the Federal University of Sergipe and CAPES has as one of its goals to develop activities that cooperate with the development of critical thinking, amplifying the ways in which those involved in the project understand the world,

1. Universidade Federal de Sergipe, São Cristóvão, SE, Brasil. 
based on the critical literacy theory. This paper aims at analyzing how literature, that many authors recognize as an ally in one's integral formation, was used in the development of one of PIBID's subprojects in which L. Frank Baum's book, The wizard of $\mathrm{Oz}(1983)$ was deployed. In order to so the execution of the project was examined, and a bibliographic qualitative research was conducted. This is an exploratory study that focuses on reflecting on the use of literature in English classes and how such use can cooperate in achieving the project's goals, based on works like Candido (1999), Coradim (2007) and Freire (1989). KEYWORDS: Literature; PIBID; english class.

\section{INTRODUÇãO}

O PIBID/Inglês (Programa Institucional de Bolsas de Iniciação à Docência) é um projeto da Coordenação de Aperfeiçoamento de Pessoal de Nível Superior (CAPES) ${ }^{2}$ ligado à Universidade Federal de Sergipe, e tem como objetivo proporcionar aos discentes da instituição que estejam cursando cursos de licenciatura com habilitação em Inglês e/ou Português-Inglês um contato inicial com as escolas públicas, o que deve contribuir para sua formação. $O$ projeto proporciona, além de contatos iniciais com a sala de aula da escola pública, discussões teóricas de textos da área de educação e ensino de língua inglesa, para que estratégias sejam traçadas a fim de melhorar a situação que envolve as aulas e alcançar seus objetivos. Os participantes são desafiados a refletir sobre como desenvolver projetos que promovam a formação crítica através do ensino de língua inglesa, utilizando os materiais que a escola disponibiliza. Portanto, os discentes em formação, orientados pelos coordenadores do projeto, procuram elaborar planos de aula que promovam o letramento crítico, utilizando a criatividade e poucos recursos materiais, adotando uma "prática educativa que tenha como eixo a formação de um cidadão autônomo e participativo” (BRASIL, 1997).

Por outro lado, existe a arte literária, que, como afirma Antonio Candido (1999), tem incumbência humanizadora, por atender à necessidade humana de se expressar, além de colaborar com o desenvolvimento da personalidade dos indivíduos, atuando na sua formação. Considerando tais informações, é possível pensar em como a literatura pode ser uma possível ferramenta no ensino e letramento de alunos. Seguindo essa linha de pensamento, o presente trabalho, tratando-se de um estudo exploratório, tem como objetivo refletir sobre como a arte literária foi

2. Agradeço à CAPES, pois, sem seu apoio, o projeto em questão neste artigo não teria sido possível. 
utilizada no desenvolvimento de um dos subprojetos do PIBID/Inglês. Para tal, é necessário pensar em como a arte literária pode atuar na formação dos alunos, analisar as práticas adotadas no subprojeto e apreciar os resultados do uso do livro The wizard of $\mathrm{Oz}(1983)$, de L. Frank Baum.

\section{A ARTE LITERÁRIA NA FORMAÇão}

Segundo Candido (1999), a produção literária e sua apreciação são baseadas na necessidade de ficção e fantasia universal e inerente ao ser humano. Ele acrescenta que há uma ligação entre fantasia e realidade; a imaginação criadora, no entanto, não reproduz o real, e está além dele, a partir do ponto de vista de Bachelard. De acordo com este (apud CANDIDO, 1999, p. 3), a verdadeira imaginação criadora é o devaneio (rêverie) que "se incorpora à imaginação poética e acaba na criação de semelhantes imagens; mas o seu ponto de partida é a realidade sensível do mundo, ao qual se liga assim necessariamente”. Essa ligação, para Candido, implica pensar no impacto da literatura na formação de identidades, quando consideramos a influência das obras que lemos na nossa personalidade.

O autor ainda fala da complexidade da função educativa da arte literária, afirmando sua força humanizadora, que integraliza os sujeitos a múltiplas visões subjetivas da realidade. Com a literatura, há um poder de formação que se opõe à "pedagogia tradicional" desejada pelos grupos sociais dominantes - esse pensamento encontra consonância no que é dito por Paulo Freire (1994) em seu livro Pedagogia do Oprimido ${ }^{3}$, no qual entende o poder no sentido marxista, isto é, dividido entre grupo dominante e grupo dominado. A literatura, dessa forma, possibilita uma educação libertadora. Mas, por carregar ideologias, a literatura pode também alienar. Candido destaca, então, a diferença entre as obras que visam elevar e propagar os "bons costumes" e aquela repleta de conflitos e complexidade, sendo esta a desejada, porque é ela que rompe com a dicotomia entre bem e mal e "humaniza em sentido profundo" (CANDIDO, 1999).

Sobre a atribuição de sentidos a obras literárias, Candido (1999, p. 6) explica que "a obra literária significa um tipo de elaboração das sugestões da personalidade e do mundo que possui autonomia de significado; mas esta autonomia não a desliga das suas fontes de inspiração no real, nem anula a sua capacidade de atuar sobre ele”.

3. Na obra, Freire (1994) fala sobre a educação bancária, em que os alunos são vistos como sem conhecimento, um local vazio em que os professores depositam conhecimento. Essa concepção, segundo ele, colabora com os grupos dominantes (os opressores), pois os alunos não são estimulados a refletir. 
A literatura permite o contato com diferentes visões da realidade e o sentimento de pertencer à humanidade. $\mathrm{O}$ leitor passa por constantes transformações de sua identidade na medida em que entra em contato com essas formas de ser humano e de ver o mundo e, consequentemente, atua na realidade, também modificando-a.

Logo, é possível afirmar que, ao se tomar contato com obras literárias, entra-se em contato com outras interpretações da realidade. E elas irão contrastar com as interpretações do leitor, mostrando-lhe outras visões, crenças e leituras do mundo, além de satisfazer sua necessidade de fantasia e ficção. Com essas afirmações, é possível pensar em como a literatura pode colaborar com a promoção do letramento crítico dos alunos; porém, é necessário, primeiramente, discutir como essa teoria é conceituada, o que é feito no tópico seguinte.

\section{Breve discussão sobre Letramento Crítico}

No Letramento Crítico, a língua é entendida como discurso no sentido foucaultiano de que ela é permeada por relações de poder - poder este que é distribuído desigualmente, além de ser ideológico; é por causa das ideologias que é possível construir sentidos a partir da materialidade dos textos (JORDÃO, 2007). A língua é, portanto, o espaço que torna tais construções possíveis de modo sempre contingente, isto é, relativo a determinados tempo, sujeito e espaço. Acrescenta-se que a língua é construída socialmente, o que implica dizer que o entendimento de mundo de um indivíduo está relacionado a suas interações com outras pessoas. Essas interpretações são permeadas por ideologias, que muitas vezes são reverberadas sem que os sujeitos percebam que o fazem (JORDÃO, 2007; JORDÃO, 2013).

Considerando que os sentidos são construídos por causa das ideologias, o Letramento Crítico propõe que os sujeitos são ativos no processo de interpretação, pois não se trata de decifrar o que o enunciador diz, mas sim de construir sentidos a partir dessa fala. Desse modo, a leitura é como um dissenso, no sentido de que o mesmo texto pode ser lido de diversas e heterogêneas formas. O leitor, portanto, deve refletir acerca de suas leituras e do que elas dizem sobre as ideologias que foram internalizadas por ele (MENEZES DE SOUZA, 2011). Nas palavras de Menezes de Souza (2011, p. 296, ênfase do autor), o Letramento Crítico pode ser definido como

não apenas ler, mas ler, se lendo, ou seja, ficar consciente o tempo inteiro de como eu estou lendo, como eu estou construindo o significado... e não achar que a leitura é um processo 
transparente, o que eu leio é aquilo que está escrito... Pensar sempre: por que entendi assim? Por que acho isso? De onde vieram as minhas ideias, as minhas interpretações?

Quando os alunos têm aulas a partir dessa teoria, eles são preparados para lidar com as diferenças, pois não há certo e errado, há diferentes leituras a partir de uma mesma materialidade textual (MENEZES DE SOUZA, 2011). Os textos literários são fontes das mais diversas visões de mundo, de modo que é possível ler textos contados a partir de diferentes perspectivas, seja a partir da fala de uma mulher, de um homem, do colonizador ou do colonizado. Isso possibilita aos alunos o contato com variadas formas de ver o mundo, diferentes ou parecidas com as suas, o que pode ajudá-los a se verem como parte de uma sociedade plural e pensar sobre qual é a sua posição nela.

No tópico seguinte, o contexto da pesquisa é apresentado, de modo a explicitar as práticas do plano de aulas em questão e como elas incorporam o texto literário a partir da teoria do Letramento Crítico.

\section{Práticas adotadas no subprojeto}

O plano de aulas ${ }^{4}$ sob análise foi desenvolvido em uma escola pública de Sergipe, especificamente, em uma turma de oitavo ano do Ensino Fundamental. Inicialmente, um questionário ${ }^{5}$ desenvolvido por um neuropsicólogo foi respondido pelos alunos da turma. $\mathrm{O}$ objetivo era conhecer melhor o perfil dos alunos; especificamente, questões emocionais. Então, o plano de aulas foi elaborado pelos participantes do projeto de acordo com o resultado dos questionários. Percebeu-se que os alunos sentiam falta da participação dos pais em suas vidas, no sentido de que eles não se envolviam nas atividades da escola, por exemplo. Desse modo, foi decidido que no plano de aulas sob análise os sentimentos seriam trabalhados e os

4. O plano de aulas foi elaborado pela autora deste artigo e por Anne Carolayne Ramiro dos Santos.

5. O questionário objetivou identificar a situação psíquica emocional dos alunos, considerando que nos momentos de observação do contexto das aulas - que foram prévios ao planejamento da sequência didática - houve afirmações recorrentes de que os alunos eram carentes emocionalmente, principalmente por parte da direção da escola e dos professores. Pensando nessa problemática, um neuropsicólogo, psicanalista e psicopedagogo foi convidado a proferir uma palestra para os participantes do subprojeto e forneceu um questionário que os alunos deveriam responder. Os dados coletados confirmaram as afirmações do corpo docente e administrativo da instituição de ensino; seus relatos, assim como os dos alunos, indicavam pouca participação da família, tanto na vida escolar dos alunos quanto no seu dia-a-dia. Por isso, houve a decisão de envolver os responsáveis e familiares em um evento na escola, para que eles pudessem ver o trabalho realizado pelos alunos. 
pais seriam convidados a participar em um evento ao fim do projeto. Nele, os alunos expuseram os artefatos elaborados e desenvolvidos nas aulas de inglês.

Pensando no questionário e nas considerações expostas anteriormente, o livro de L. Frank Baum, The wizard of $\mathrm{Oz}$ (1983), foi selecionado. Além de abordar os sentimentos através de personagens como o leão covarde, que descobre que é corajoso no fim da história, o livro também explora a conexão da personagem-protagonista com seu lar.

O plano engloba cinco aulas e uma culminância. Na primeira aula, um teatro de fantoches foi apresentado aos alunos, considerando que muitos deles poderiam não conhecer o livro e que o teatro poderia ajudar na compreensão dos textos em língua inglesa. E então, com a sinopse do livro, as estratégias de leitura skimming e scanning foram trabalhadas. O skimming pode ser definido como o ato de ler um texto rapidamente para entender sua ideia principal, enquanto o scanning consiste na busca por informações específicas, como o nome de personagens, por exemplo (SOUZA et al., 2005). Os alunos foram encorajados a utilizar as estratégias para ler a obra, para que nas aulas seguintes o conteúdo fosse desenvolvido com base nas leituras.

Na segunda aula houve um debate acerca da obra. Nesse momento, os alunos expuseram suas interpretações da história, mostrando que, com base em um mesmo texto, diferentes leituras surgem, como argumenta a teoria do Letramento Crítico discutida anteriormente. Então, os alunos foram questionados acerca do que mudariam no texto, se é que mudariam algo. Além disso, foi pedido que eles imaginassem como seria o conteúdo do livro se ele tivesse sido escrito contemporaneamente. A ideia era estimular os alunos a lerem criticamente, comparando o contexto apresentado no livro à sua própria realidade, refletindo, dessa forma, sobre ela.

Em seguida, na mesma aula, o vocabulário referente a sentimentos foi abordado com trechos da obra. Conhecendo o texto, os alunos deveriam utilizar esse conhecimento para entender o que as palavras significavam e como elas estavam sendo usadas naquele contexto. Essa abordagem pode ser caracterizada como indutiva - defendida pela Abordagem Comunicativa (MATTOS, VALÉRIO, 2010) e por Kumaravadivelu (2006) na condição pós-método - porque a estrutura gramatical não foi explicitamente explicada; sendo expostos a insumo linguístico e com base no contexto, os alunos puderam perceber o significado e uso das palavras. Houve, desse modo, um trabalho com a língua inglesa em que ela foi abordada como uma construção social intrinsecamente ligada ao seu contexto, como é recomendado por documentos oficiais da educação (BRASIL, 2018). Essa prática se opõe ao ensino 
estrutural da língua, em que a gramática é explicada aos alunos de forma isolada de um contexto social em que a língua é utilizada para negociação de sentidos.

$\mathrm{Na}$ tentativa de estimular o "ler, se lendo" (MENEZES DE SOUZA, 2011, p. 296), uma atividade denominada "dinâmica do espelho" foi realizada na sala de aula. Nessa dinâmica, que tem como objetivo despertar a reflexão dos alunos sobre si mesmos, eles olham para dentro de uma caixa, inicialmente sem saber o que está dentro dela, e descobrem que há um espelho; então, usando o vocabulário anteriormente aprendido, eles escrevem ou falam o que sentiram ao se verem. Todos os alunos optaram por escrever as respostas em seus cadernos e mostrá-las apenas à professora. As palavras mais utilizadas foram: sad (triste), angry (zangado), shy (tímido), confused (confuso) e bored (entediado).

Na terceira aula foi trabalhada a caracterização das personagens, usando trechos do livro. A ênfase se deu em como os adjetivos foram utilizados para falar de características das personagens, além de observar como os adjetivos se relacionavam com as outras palavras nas frases. Nesse momento, os alunos puderam observar como, na prática, os adjetivos podem ser utilizados na construção de personagens dentro de um texto literário, considerando a relação dessas palavras com as outras presentes nas sentenças. Essa atividade foi importante para que os alunos fossem expostos a exemplos do uso de adjetivos em narrativas, pois eles precisaram fazê-lo posteriormente em suas próprias histórias. Foi a partir do fim dessa e durante a quarta aula que os alunos, divididos em grupos de cerca de cinco pessoas, criaram e escreveram textos literários em língua inglesa.

A maior parte da produção, cujo tema era livre, ocorreu na sala de aula, com o auxílio de dicionários de português-inglês. Os alunos escreveram tanto sobre si mesmos - muitas vezes inseridos em contextos fantásticos - quanto sobre personagens fictícios e foram capazes de utilizar adjetivos na construção destes, o que indica a importância das atividades anteriores em que eles precisaram refletir sobre

6. Considerando a ênfase em questões identitárias e na saúde psíquico-emocional dos alunos, a dinâmica do espelho foi proposta. O seu objetivo foi levar os alunos a refletirem sobre como eles se sentiam ao pensarem em si mesmos e de que forma eles se enxergavam. Dentro de uma caixa de papelão, foi colocado um espelho. No entanto, os alunos olhavam dentro da caixa ignorando esse fato. Dessa maneira, utilizouse da surpresa para que eles pudessem perceber seus os pensamentos que surgiriam de forma espontânea. O modo como se viam definia quais dos vocabulários eles utilizariam para descrever seus sentimentos ao olharem para si mesmos. A língua foi, portanto, abordada dentro de um contexto de uso significativo, em que os alunos precisavam entender as palavras para utilizá-las na atividade, ao mesmo tempo em que refletiam sobre o impacto de suas escolhas linguísticas. 
o uso dessas palavras e sua relação com o modo em que eles enxergavam tanto eles mesmos quanto o mundo a sua volta. Além de escreverem narrativas, os alunos confeccionaram capas de livros para elas, como mais uma maneira de se expressarem artisticamente. Para tanto, foram utilizadas caixas de papelão, cartolinas, cola, folhas de papel ofício, tesoura e outros materiais, como glitter e lápis de cor. Por fim, para engajar os pais dos alunos, foi organizada uma culminância - pequeno evento que ocorreu no pátio da escola, em que as produções foram expostas tanto para convidados (familiares/responsáveis, amigos) quanto para a comunidade escolar.

\section{ANÁlise dos Resultados}

Atualmente, a leitura de livros se mostra pouco atraente para muitos jovens. Quando o professor solicita que os alunos realizem essa tarefa, muitos recorrem à leitura de resumos ou resenhas disponíveis na internet. Esse assunto foi levantado para discussão na primeira aula do plano e a grande maioria dos alunos concordou que nenhuma dessas leituras dispensa a do livro.

Sobre a importância da leitura, Freire (1989) afirma que antes do contato com a expressão escrita, há o contato com a expressão oral e é nesta que as leituras do mundo de outras pessoas, especificamente as que fazem parte do círculo social do indivíduo, são apreendidas. A partir disso, ele fala da alfabetização não mecânica como um ato criador, pois as palavras são representações da realidade impregnadas de leituras e mais leituras do mundo; portanto, ler é criar uma nova interpretação, é reescrever o que foi lido.

A leitura do mundo precede a leitura da palavra, daí que a posterior leitura desta não possa prescindir da continuidade da leitura daquele. Linguagem e realidade se prendem dinamicamente. A compreensão do texto a ser alcançada por sua leitura crítica implica a percepção das relações entre o texto e o contexto (FREIRE, 1989, p. 9).

A leitura, então, mostra-se muito importante na formação crítica. Os PCN também recomendam a leitura em língua estrangeira, defendendo que isso pode colaborar com o "desenvolvimento integral do letramento do aluno" (BRASIL, 1997, p. 20). Por esse motivo, sua abordagem é relevante não somente nas aulas de língua materna como também nas de língua inglesa. Essa afirmação pode levar muitos a pensar que os alunos das escolas públicas não têm o conhecimento necessário para 
entender um texto em língua inglesa, demonstrando descrença na efetividade do ensino nesse contexto, como mostrado na pesquisa de Boa Sorte e Silva (2018). Essa constatação parte tanto de professores quanto de alunos. Diversas vezes, ao entrarem em contato com o texto do livro, os alunos falavam frases como "está em inglês; não vou entender nada". Porém, é observando textos que é possível perceber como as frases estão estruturadas, com eles é também possível aprender vocabulário. São proporcionadas ao leitor inúmeras vantagens no que diz respeito a aprender a língua. Percebeu-se que os alunos conseguiram entender melhor como usar um adjetivo para caracterizar uma personagem, por exemplo, observando como isso foi feito no livro. Isso ficou claro nas histórias que eles escreveram em língua inglesa. Além disso, o trabalho com as estratégias de leitura, skimming e scanning, possibilitou aos alunos maneiras de extrair informações e ideias do texto, mesmo sem a proficiência na língua inglesa, o que demonstra a importância de expor os alunos a textos na língua-alvo e a formas de lê-los.

Acrescenta-se, ainda, que um livro escrito em outra língua traz em si aspectos de outra cultura, como é o caso de The wizard of $\mathrm{Oz}(1983)$. Através da discussão com os alunos na segunda aula, fez-se um contraponto do que está na obra com seus contextos, levando em consideração o conhecimento prévio dos discentes. A maior parte dos estudantes afirmou que mudaria a história, alguns falaram que o cenário poderia ser uma favela ao invés de $\mathrm{Oz}$, outros propuseram que a protagonista fosse negra e tivesse cabelos cacheados. Também foi muito comentada a falta de "ação" no livro. Para eles, a história era muito "parada", deveria ter mais lutas, mais suspense. Com isso, vemos que foi criado um diálogo entre o que está no texto e o que o aluno acredita que gostaria de ler. O processo de leitura é construído socialmente, como defende o Letramento Crítico (JORDÃO, 2007; MENEZES DE SOUZA, 2011) e de acordo com Coradim (2007). Isso quer dizer que cada um interpretou o texto de acordo com seu conhecimento prévio, construído nas interações sociais. Portanto, as afirmações dos alunos revelam seu contato com histórias de ação, seja através de filmes, livros, jogos ou até mesmo da realidade deles, que pode expô-los a cenas de violência. Também se percebe uma desconstrução das características das personagens e do cenário do livro para reconstruí-los de uma maneira em que se pareçam mais com os leitores e com as pessoas com quem os leitores interagem socialmente (no cotidiano ou através da televisão e/ou redes sociais). Os alunos utilizariam adjetivos diferentes dos utilizados pelo autor do texto trabalhado porque as escolhas do escritor corroboraram na criação de personagens que não refletiam suas identidades e tampouco as das pessoas a sua 
volta. Houve, portanto, uma apropriação da língua para agir e transformar a história trabalhada, para que ela representasse os alunos-leitores. Esse processo de (des/re) construção é importante no desenvolvimento crítico dos alunos, pois nossas leituras têm consequências sociais e são ideológicas. É necessário perceber que há outros modos de ler, igualmente ideológicos, para que o aluno seja consciente acerca de que ideologias suas leituras reverberam e quais são as consequências delas. Dessa maneira, os alunos devem perceber que as escolhas sobre quais adjetivos usar, por parte do autor, foram ideológicas e intrinsecamente relacionadas às suas leituras de mundo, mas que há outras possibilidades e formas de ler que são igualmente válidas e ideológicas.

Coradim (2007, p. 26) ainda acrescenta que a atitude dos alunos de dizer o que mudariam no livro se caracteriza como uma leitura crítica. A autora argumenta que "a leitura como prática social faz com que o leitor se torne presente na leitura que realiza. Isso o leva a uma conduta crítica da leitura, sendo capaz de refletir sobre o que lê e para que lề. Nesse tipo de leitura, há uma interação entre o texto e o leitor, indo além do processo de decodificação. As interpretações ocorrem com base nas experiências prévias daquele que lê e por esse motivo surgem diferentes leituras sobre a mesma materialidade textual. Dessa maneira, o leitor crítico não deve ser passivo na leitura, mas deve ver que o autor não é uma autoridade cuja palavra é incontestável. É necessário questionar, considerando língua como discurso, não verdade absoluta:

a possibilidade ou o desejo por discursos "verdadeiros" é considerada ilusória. [...] a questão que se apresenta nesta perspectiva não é mais a de certo ou errado a partir de um referente exterior a uma afirmação, e sim a do reconhecimento social de uma afirmação como sendo mais ou menos legítima" (JORDÃO, 2007, p. 26).

Portanto, ao discutir sobre as suas interpretações, os alunos puderam perceber que diferentes significados foram construídos e nenhum deles estava certo ou errado. Isso não quer dizer que qualquer interpretação vale, pois ela deve partir da materialidade textual; por exemplo, a partir da frase "eu sou alta", quais sentidos podem ser construídos? Sobre a questão de certo ou errado, aquele é, na maioria das vezes, a leitura socialmente legitimada ou a que o livro ou o professor consideram como a verdadeira. $O$ ensino, porém, não deve ser uma imposição de verdades, mas sim um espaço para reflexões e (des/re) construções.

Coradim (2008) explica a leitura crítica como sendo uma 
visão de texto [que] envolve leitura de várias tipologias textuais, todas contextualizadas, onde o objetivo é desmascarar as ideologias presentes nas produções escritas. [...] Espera-se um leitor crítico, capaz de ler nas entrelinhas, indagar e perceber as relações de poder existentes nos textos. A concepção de linguagem, nesse contexto, se distancia da visão de língua tida somente como sistema linguístico. Leva-se em conta seu contexto de produção e as interações nas quais ela se concretiza.

O processo, desse modo, envolve a reflexão acerca do que foi escrito por um autor, com ênfase na percepção das ideologias presentes no texto. Esse é um dos aspectos em que a leitura crítica entra em dissonância com o Letramento Crítico. Na primeira visa-se desmarcar as ideologias presentes no discurso do autor, para que assim o leitor consiga se libertar da manipulação. A leitura ainda é restrita ao texto, não são exploradas, por exemplo, questões sociais a ele relacionadas (CORADIM, 2008). Diferentemente, com o Letramento Crítico, pouco importa a intenção do autor de manipular através das ideologias porque a língua é sempre ideológica; o que interessa é como o leitor constrói sentidos e que ideologias perpassam suas interpretações, que são frutos de práticas sociais. Logo, a reflexão sobre a leitura deve ir além da materialidade do texto, abrindo-se espaço para reflexões acerca do social (JORDÃO, 2013).

\section{CONSIDERAÇões Finais}

A literatura, arte das palavras, é fonte para construção de sentidos. Este artigo mostra que é importante trabalhar com textos literários na sala de aula de língua inglesa de modo a estimular o pensamento crítico dos alunos, no sentido de que eles se coloquem como agentes no processo de interpretações e reflitam acerca delas, procurando entender o que suas leituras dizem sobre eles mesmos. $O$ texto literário também pode contribuir com o reconhecimento da posição social do aluno, que, ao ler, tem a oportunidade de conhecer personagens de diferentes realidades sociais e refletir sobre elas e sobre sua própria realidade. Para atingir tais potencialidades, o Letramento Crítico se mostrou eficaz e possibilitou um trabalho com a língua inglesa que a abordava como discurso e prática social, além de estimular o pensamento crítico.

O texto literário também estimulou a imaginação dos alunos, contribuindo com o processo de escrita. Os textos escritos pelos alunos tinham como pontos comuns o horror e a ação, em narrativas que incluíam morte, fantasmas e monstros, exceto pela produção de um dos grupos, que retratava o cotidiano repetitivo de um homem 
comum que trabalhava todos os dias. Como foi discutido, a imaginação está relacionada à realidade (CANDIDO, 1999); desse modo, foi mostrado que tanto no processo de leitura quanto no processo de escrita os alunos resgataram suas realidades, o que inclui também os diferentes conteúdos que eles consomem (filmes, leitura de textos literários, novelas etc.). Isso porque a construção de sentidos, como foi argumentado, tem base nas interações sociais dos indivíduos, por meio das quais ideologias são internalizadas. Na sala de aula, a partir da perspectiva do Letramento Crítico, deve-se levar os alunos a questionar e refletir sobre suas próprias leituras e as ideologias que as permeiam. A dinâmica do espelho contribuiu com o processo de autorreflexão dos alunos, que puderam se ver e expressar como se enxergavam, utilizando adjetivos. Posteriormente, eles contrastaram suas imagens com as dos personagens no livro, ao dizerem o que mudariam. A dinâmica também preparou os alunos para pensar, no momento da escrita, as semelhanças e diferenças entre os personagens construídos e eles mesmos, considerando os adjetivos utilizados para descrever cada um e/ou suas ações.

Desse modo, é possível concluir que a arte literária colaborou no alcance dos objetivos do PIBID/inglês, e que, além de satisfazer a necessidade de fantasia/ficção inerentes ao ser humano (CANDIDO, 1999), ela pode contribuir com o desenvolvimento do pensamento crítico dos alunos. Porém, o modo como o texto literário é abordado nas aulas faz toda diferença nesse processo.

No que diz respeito à participação dos pais e responsáveis dos alunos no dia do evento em que suas produções foram expostas, houve pouca adesão, pois apenas quatro familiares estiveram presentes. Isso demonstra a necessidade de envolver essas pessoas na vida escolar dos alunos. Esse acontecimento indica ainda que cumprir esse objetivo é um desafio que exige um trabalho contínuo por parte da escola, isto é, ele não pode ser resolvido com um evento esporádico.

\section{REFERÊNCIAS}

BAUM, L. F. The wizard of Oz. New York: Shocken books, 1983.

BOA SORTE, P; SILVA, N. S. M. English Teaching Conceptions: cognitive processes on ongoing professional development. Cocar, Belém/PA, v. 12, n. 24, p. 3-24, 2018.

BRASIL. Base Nacional Comum Curricular - BNCC, versão de novembro de 2018. Disponível em: http://basenacionalcomum.mec.gov.br/images/BNCC_EI_EF_110518_versaofinal_site.pdf. Acesso em: 19 ago. 2019.

BRASIL. Parâmetros Curriculares Nacionais (PCNs). Introdução. Ensino Fundamental. Brasília: MEC/SEF, 1997. 
CANDIDO, A. A literatura e a formação do homem. Remate de Males, Campinas/SP, p. 81-90, 1999. Disponível em: https://periodicos.sbu.unicamp.br/ojs/index.php/remate/article/ download/8635992/3701. Acesso em: 22 mai. 2017.

CORADIM, J. N. Leitura crítica e letramento crítico: idealizações, desejos ou (im) possibilidades? 2008. Dissertação (Mestrado em Estudos da Linguagem). Programa de Pós-graduação em Estudos da Linguagem, Universidade Estadual de Londrina, Londrina, 2008.

CORADIM, J. N. Leitura crítica em língua inglesa. Monografia (Especialização em Ensino de Línguas Estrangeiras). Universidade Estadual de Londrina, Londrina, 2007.

FREIRE, P. A importância do ato de ler: em três artigos que se completam. 23. ed. São Paulo: Autores Associados, Cortez, 1989.

FREIRE, P. Pedagogia do Oprimido. Rio de Janeiro: Paz e Terra, 1994.

JORDÃO, C. M. Abordagem comunicativa, pedagogia crítica e letramento crítico - farinhas do mesmo saco? In: ROCHA, C. H.; MACIEL, R. F. (Org.) Língua estrangeira e formação cidadã: por entre discursos e práticas. Campinas/SP: Pontes Editores, 2013, p. 69-90.

JORDÃO, C. M. O que todos sabem.... ou não: letramento crítico e questionamento conceitual. Revista Crop, p. 21-46, 2007.

KUMARAVADIVELU, B. Understanding Language Teaching: From Method to Postmethod. London: Lawrence Erlbaum Associates, 2006.

MATTOS, A. M. A.; VALÉRIO, K. M. Letramento crítico e ensino comunicativo: lacunas e interseções. RBLA, Belo Horizonte, v. 10, n. 1, p. 135-158, 2010.

MENEZES DE SOUZA, L. M. T. O Professor de Inglês e os Letramentos no século XXI: métodos ou ética? In: JORDÃO, C. M.; MARTINEZ, J.Z; HALU, R. C. (Org.). Formação (Des) formatada: práticas com professores de língua inglesa. São Paulo: Pontes, 2011, p. 279-303.

SOUZA, A. G. F. et al. Leitura em língua inglesa: uma abordagem instrumental. São Paulo: Disal, 2005.

\section{SOBRE A AUTORA}

Nayara Stefanie Mandarino Silva é graduanda em Letras Português e Inglês (Universidade Federal de Sergipe). É professora de inglês da rede ANDIFES Idiomas sem Fronteiras e pesquisadora da Universidade Federal de Sergipe. Tem experiência nas áreas de Letras, Linguística e Educação, com pesquisa nos seguintes temas: tecnologias no ensino de línguas, formação de professores, ensino de língua inglesa e educação no período pombalino. É integrante do grupo de pesquisa Núcleo de Estudos de Cultura da UFS - Pólo autónomo internacional do CLEPUL: história, cultura e educação.

E-mail: nayaramandarino@hotmail.com.

Recebido em 11 de janeiro de 2019 e aprovado em 02 de fevereiro de 2020. 